\title{
The great escape
}

Jane Howorth is the organizer of Britain's biggest hen party, a group of 900 volunteers dedicated to improving the lives of millions of chickens employed in the UK egg industry. They seek out new homes for birds destined for the slaughterhouse at the end of their productive careers, and work to improve understanding of hen health and welfare. She told John Bonner about their plans to support clinical research on the common diseases affecting backyard poultry.

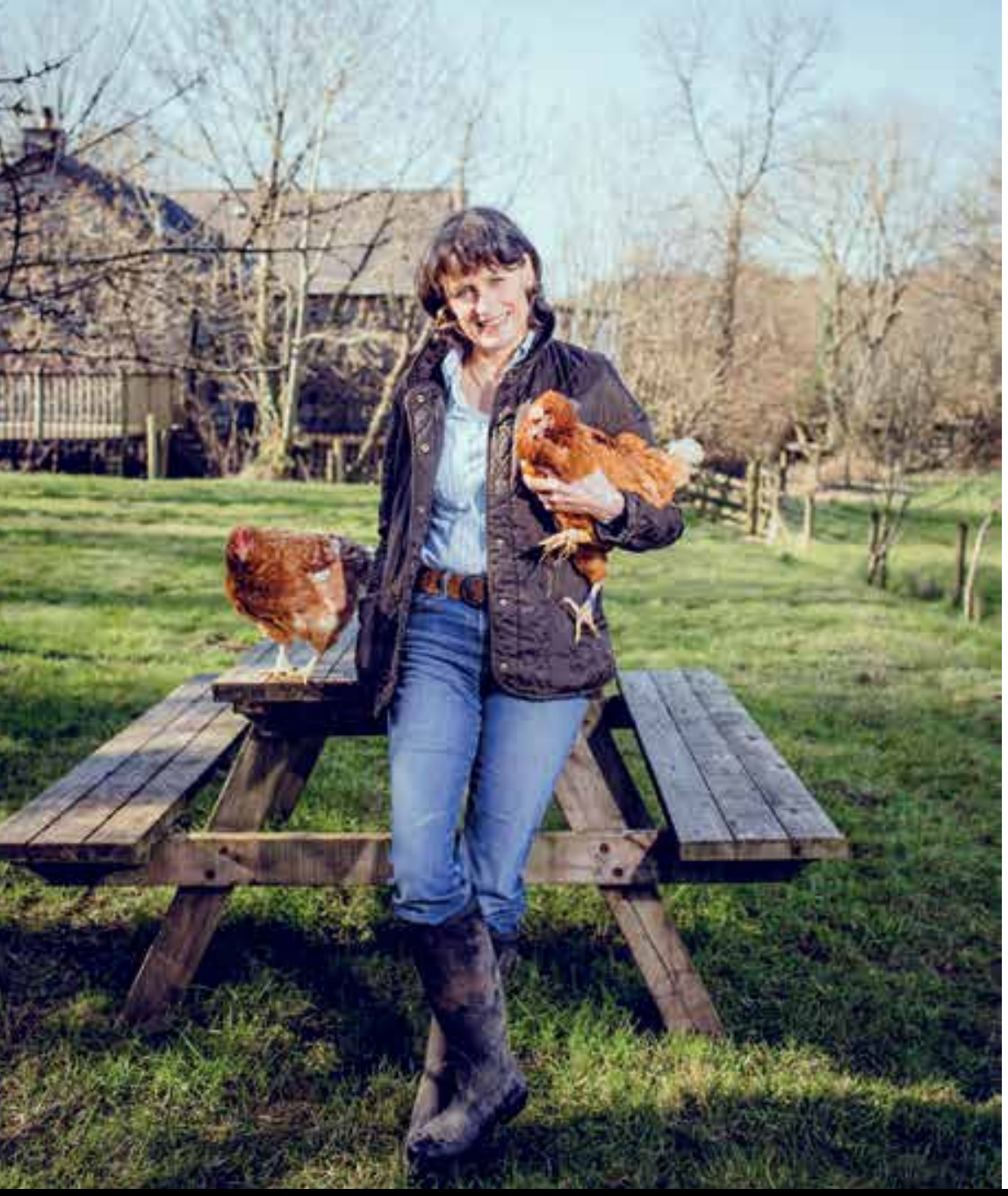

n 2005 Jane set up the British Hen Welfare Trust as an organization for rehoming spent battery hens but her mission to nurture happier hens had taken embryonic form years earlier when she was a teenager in the late 1970s.

After watching a BBC documentary on egg production in battery cage systems, she began writing letters to MPs, farmers and food retailers demanding to know why it wasn't possible to offer the birds healthier and more fulfilling lives.

As she continued her campaign for better welfare, she found that growing numbers shared her concerns. In its first 14 years, the trust has found enough people with an interest in keeping spent hens to rescue nearly 750,000 birds from slaughter. The organization now has 15 regular staff and a huge network of volunteers responsible for recruiting new re-homers and offering them support and advice.

In 2019, the trust extended the lives of more than 67,000 hens but Jane shows little interest in the exact figures. "These birds are only a small percentage of the numbers used in the industry, but we were never going to save them all. It is not about the numbers, it is about the educational benefits of the birds that we rehome. These birds are our most effective tool for influencing the shopping habits of consumers."

\section{There has been massive investment by the British egg industry in free range production and they deserve our help.}

In 2012, EU regulations (the Laying Hens Directive) came into force banning the barren battery cages that had so appalled Jane as a teenager. Although she would like to see all the UK's eggs produced in free range systems she accepts that the enriched colony cages that have replaced the old battery systems are a step forward. The trust is very supportive of the UK egg industry's efforts to raise welfare standards and wants to discourage consumers from buying the millions of eggs that are imported from countries still using the systems banned in the EU, she says.

"When we started, about $32 \%$ of UK egg production was free-range, by 2017 that had gone up to more than $60 \%$. We have played a part in this, but there has been massive investment by the British egg industry in free range production and they deserve our help."

Hens bred to produce much greater numbers of eggs than their ancestral jungle fowl will have reached the end of their commercially useful lives at about 18 months old. But they can survive for 2 or 3 years and will continue producing eggs, albeit at a reduced rate. Indeed, Jane notes that one of her own hens reached the remarkable milestone of 12 years so their longevity 


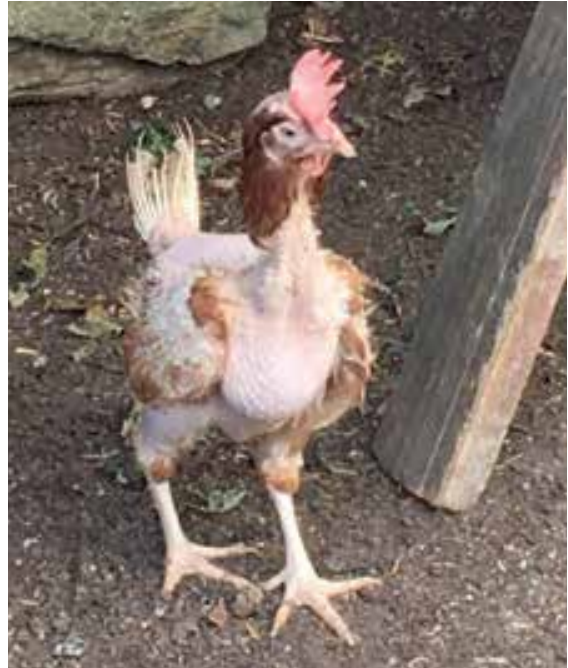

FIGURE 1: Dot arrives in her new home.

will be largely due to the quality of nutrition and husbandry that they receive. The trust's staff and volunteers put considerable effort into educating their re-homers on feeding and general care of the birds, and also work closely with Defra in disseminating information on other issues, such as biosecurity.

At the time of rehoming, it may appear unlikely that the birds will be around for the long term, as they will have lost much of their plumage due to feather plucking by their flockmates (Figure 1). However, Jane points out that this problem isn't confined to birds in colony cages, it happens in barns and any intensive management system. Their feathers will regrow quickly when the birds have more space and less competition for resources (Figure 2).

There are also many more important health issues to address. The most common disease affecting rehomed hens is egg peritonitis, which fits into the treatable but challenging category.

Jane says her own vet, Marcella Perversi of the West Ridge Veterinary Practice in Winkleigh, Devon is one of a limited number of UK practitioners skilled in the surgical treatment of this condition. This involves spaying the hen to prevent any further egg production and removing the yolk residue from the bird's abdomen that can be the focus of a bacterial infection. There are no licensed medical treatments although the canine hormonal product Suprelorin may be used to chemically neuter the birds under the cascade system, she suggests.

Other diseases that will commonly affect backyard poultry include bumblefoot, bone breakages,

gastrointestinal disturbances (sour crop, impaction, prolapsed cloacas, vent gleet, etc.) and both internal and external parasites. Many small animal practitioners have found that they are asked to advise on these conditions with increasing regularity and therefore will welcome the recent publication of the BSAVA Manual of Backyard Poultry Medicine and Surgery.

The number of practices with an active interest in non-commercial poultry has also been growing over the past decade and these are listed on the hen friendly vets page of the BHWT website (https://www.bhwt.org.uk). Jane acknowledges that the coverage is still patchy and is currently working with the University of Nottingham on a Massive Open Online Course that will give practitioners access to further training in a clinical discipline that is likely to produce an increasing proportion of the caseload in first-opinion practice.

But she is also aware that the scientific evidence needed by practitioners to provide a higher quality service to non-commercial poultry keepers is often unavailable. That is why the trust is funding a programme of support for poultry health research. There will be grants of between $£ 1000-£ 3000$ which will be available from 1 February 2020. Suitable projects will be chosen by a scientific advisory committee chaired by the noted avian vet Neil Forbes.

"Applications are invited from UKbased veterinarians, academics, other qualified professionals and agricultural and veterinary students wishing to undertake research that will improve and benefit the health, welfare and longevity of pet chickens. We are interested in applications that will have a rapid and positive impact

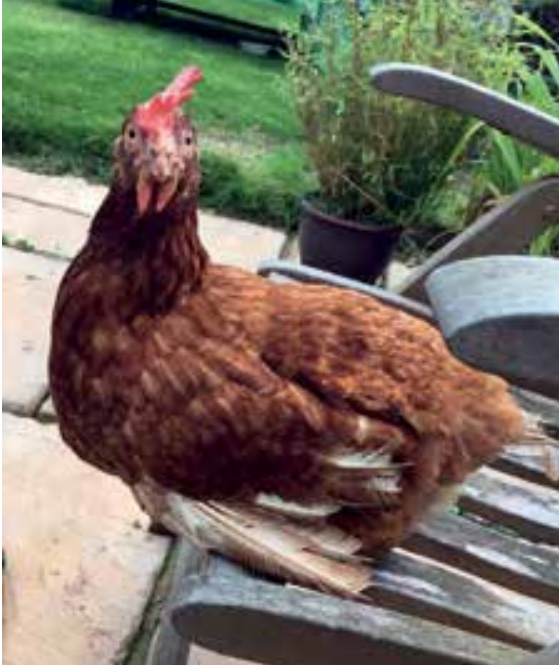

FIGURE 2: Dot having settled into her new home.

on the way diseases in hens are diagnosed, managed or treated in general practice, as well as at a specialist level," Jane explains.

She points out that hens have become the fifth most common terrestrial pet species after dogs, cats and rabbits and she believes that their popularity will continue to grow. "It is a very rewarding hobby. When they first arrive, the hens are bewildered and threadbare but they gradually blossom into well feathered, active and reasonably productive birds that make fabulous pets. It has been estimated that there are around a million people keeping backyard birds these days and the growth in numbers doesn't appear to be slowing. About half of the birds that we rehome go to people who are rehoming for the first time. Those that are repeat rehomers may be on their fourth or fifth generation of birds. It is really quite addictive," she said. IC

AVAILABLE FROM BSAVA
BSAVA Manual of
BaCkyard Poultry Medicine
and Surgery
Edited by: Guy Poland and Aidan Raftery
This new BSAVA manual provides good quality information on chickens, turkeys,
ducks, geese, guinea fowl, ornamental pheasants and peafowl to help veterinarians
deliver the level of care to backyard birds that clients are increasingly coming to expect.
To purchase a print copy go to www.bsava.com/shop.
An online version is also available from www.bsavalibrary.com/manuals.

